\title{
Life Cycle Assessment of Reprocessed Cross Laminated Timber in Latvia
}

\author{
Ilze VAMZA ${ }^{1 *}$, Fabian DIAZ ${ }^{2}$, Peteris RESNAIS ${ }^{3}$, Antra RADZIN̦A $^{4}$, Dagnija BLUMBERGA ${ }^{5}$ \\ 1,2,4,5 Institute of Energy Systems and Environment, Riga Technical University, 12-k1 Azenes street, Riga, \\ LV-1048, Latvia \\ ${ }^{3}$ SIA FUNDUSS, 'Tiltakrogs', Ieriki, Drabešu parish, Amatas reg. LV-4139, Latvia
}

\begin{abstract}
It is expected that Cross-laminated timber (CLT) and other engineered wood products will experience rapid growth in the coming years. Global population growth is requiring more housing units, at the same time the negative impact of construction industry cannot stay in the same level as today. Alternatives for concrete and steel reinforced structures are being explored. CLT has proven to be an excellent substitution for concrete regarding construction of buildings up to eight storeys high. In addition to much lower environmental impact, construction process using CLT takes significantly less time due to pre-cut shapes required for specific project. Despite mentioned benefits, there are considerable amount of CLT cuttings generated in this process. Due to irregular shape and small dimensions of these cuttings they are useless for further use in construction. By applying re-processing technology described in this paper, around $70 \%$ of generated cuttings can be re-processed into new CLT panels. In this paper we are evaluating the environmental benefits of re-processing these cuttings into new CLT panels versus business-as-usual scenario with waste disposal. Life cycle assessment results showed significant reduction of environmental impact for the scenario of CLT cutting re-processing.
\end{abstract}

Keywords - Avoided burden; construction; green buildings; eco-efficiency; engineered wood products

\section{INTRODUCTION}

In lines with the Europe's Green Deal and overall ambition to reduce the carbon footprint of human activities, building and construction industries are a good direction to look. According to life cycle assessment on environmental impact of a dwelling in EU, individual family houses have the biggest negative impact per person per $\mathrm{m}^{2}$. Significant negative impact is from building construction - mainly due to the metal that has been used for concrete reinforcement, used metal has $40 \%$ effect on Human toxicity. Additionally, production of conventional building materials like concrete and bricks has considerable negative environmental impact [1]. According to European Commission, building construction and use consumes half of all the extracted materials and produced energy [2]. Hence improvements in construction and building industries could bring significant positive change regarding environmental impact of human activities. Promising field of improvement is the use of innovative building materials with less negative environmental impact but comparable functional properties.

\footnotetext{
* Corresponding author.

E-mail address: ilze.vamza@rtu.lv
} 
As abovementioned, concrete and steel have the most negative impact. In order to reduce the global warming potential (GWP) of building construction and exploitation, alternatives to reinforced concrete are being explored. For comparison - GWP of concrete with $\sim 40 \mathrm{MPa}$ strength is from 120 to $60 \mathrm{~kg} \mathrm{CO} / \mathrm{m}^{3}$ for some greener concrete variations [3], in contrast cross-laminated timber with the same strength has only $40 \mathrm{~kg} \mathrm{CO} / \mathrm{m}^{3} \mathrm{GWP}$ [4]. Wood based products were popular in the mid-twentieth century but increasing fire safety concerns and demand for high-rise buildings motivated the use of steel reinforced concrete. Up to 2014 cement industry experienced steady growth globally reaching $4 \mathrm{Gt}$ of annual production, since then the annual production volumes have not changed [5]. Search for more sustainable options have led to engineered wood products (EWP), these materials are made out of various types of primary and secondary timber. Wood biomass has become desirable again, this time it is due to its added benefit of carbon storage. Naturally timber has great load bearing capabilities, EWP exploit these properties and offer structural materials with much lower environmental impact than concrete. Wood-based panel market is growing globally, by the estimates the size of it in 2019 was 124.416 billion euros and it continues to grow. Geographically the biggest market share is held by Asia Pacific region, it accounts for around $54 \%$. Europe holds around $24 \%$ of the wood-based panel market [6]. Wood-based panel market can be divided in terms of application or product category. Some of the most popular products are medium density fibreboards, particleboards, plywood, softboard and hardboard. Product popularity varies in different regions, for example - oriented strand boards (OSB) are the most popular products in United States. In Europe the most popular ones are particleboards and medium density boards (MDF) holding around $75 \%$ of Europe's market. Cross laminated timber is product that can serve as an alternative in construction, this product is developed in Central Europe and at this point its market share have not even reached half a billion. Nevertheless, material like cross-laminated timber (CLT) is a good example of EWP [7]. CLT boards are produced from planks adhered together layer by layer. To ensure higher mechanical strength, layers are oriented on top of each other to $90^{\circ}$ in relation to bottom layer. Mechanical properties of the final panels are dependent on used adhesive, thickness of the separate layers and type of wood. Lower grade planks can be used, but in order to achieve uniformity of the material, knots are usually cut out of the planks before gluing them together [8]. Overall EWP category is becoming more popular in the construction industry [9]. Another benefit of CLT and other EWP is their low density, this is important factor for building mid- and high-rise buildings as the structures of lower levels need to hold up all the weight above them. Higher strength to weight ratio is more desirable [10].

Hemström et al. 2011 [11] research concluded that stakeholder attitudes towards wood in construction are changing. In Sweden restrictions on mid-rise wood constructions have been lifted since 1994 [11], in Latvia only since 2015 it is allowed to build up to six story buildings from wood, but only if evacuation routes are fire proofed and equipped with sprinklers [12]. Sprinkler systems increase the price of the project; hence developers can steer away from wood solutions and seek cheaper options. Nevertheless, 15 years after lifting restrictions architects in Sweden still considered concrete as the most reliable material in comparison to steel and wood, even if wood ranked highest in environment, design and project categories. Project category included costs, construction time, work environment and transport [11].

Despite the stakeholder attitude towards building with wood, EWP like medium-density fiberboard, CLT and laminated veneer lumber (LVL) have proven that their physical properties are similar to widely used materials with higher negative impacts on environment. For example - wood fiber insulation materials thermal conductivity matches the one of rockwool, with the added benefit of increased heat capacity. Due to LVL considerable compressive strength this material can replace steel beams however CLT has considerable 
compressive and flexural strength, hence it can be used in weight bearing wooden constructions [9]. According to OECD [13] globally life quality is increasing, as mentioned by FAO [14] this is one of the factors demand for wood-based boards are expected to rise even more - as people choose to build bigger houses and change their furniture more often [1]. Hence wood-based solutions that could provide consumers with the same functional qualities could be well accepted not only by environmentally conscious consumers, but developers who will need to find a way to meet the growing customer demand.

In the mid-rise wood building segment popular choice has become CLT, there are multiple examples of eight-story projects [10], [11]. As noted by Hemström et al. pre-made panels is one of the reasons construction with CLT is significantly faster than with other materials like bricks [11]. Specific shapes can be cut prior material transportation to construction site. This approach allows to cut down the onsite operation time and reduces the transported mass and fuel consumption in return. Nevertheless, all the cuttings are sent to waste stream as their dimensions are useless for application in construction. These cuttings account for around $15 \%$ of produced CLT [15]. Usual treatment of CLT waste is incineration as added chemical inhibit biodegradation making it unsuitable for landfills [10].

Life cycle assessment have been often used to compare environmental impact during construction, exploitation and end of life stages of reinforced concrete structures versus CLT structures [16]. At this point many papers have been published on this topic evaluating various geographical cases [4], [10], [16], [17]. Nevertheless, the amount of cuttings and their impact have not yet been studied. In this paper we are looking into environmental impacts of reprocessing CLT cuttings into functional full size CLT panels in comparison with business-as-usual scenario of CLT waste disposal. Technology for CLT reprocessing is developed in lines with industrial research and all the mass flows are based on the results of it.

\section{Methods}

\subsection{Cross-Laminated Timber Reuse}

Reprocessing of the panels consisted of five main steps: squaring, finger-joint profiling, adhesive application, pressing and cutting to required dimensions. Custom made set of production machinery was used for carrying out the CLT reprocessing process. Formatting was done manually by using hand tools. Finger joint milling and pressing was done on specifically designed prototype machinery. Electric saw with $77 \%$ efficiency consumed $0.01 \mathrm{kWh} / \mathrm{m}$, hydraulic press ( $82 \%$ efficiency) was able to press maximum of three panels consuming $0.09 \mathrm{kWh}$ per pressing. Finger joint cutting required feeder and cutter with $77 \%$ and $89 \%$ efficiencies, respectively, overall finger joint cutting required $0.16 \mathrm{kWh} / \mathrm{m}$. CLT cuttings left from construction were reprocessed into new master panels with dimensions of 3 by 6 meters. In order to make the reuse of CLT panels efficient, leftover cuttings had to be sorted in order to organize them by thickness. Developed technology allows recycling of CLT boards with maximum thickness of $160 \mathrm{~mm}$. Machinery is limited to only process cuttings wider than $800 \mathrm{~mm}$. Cuttings with smaller dimensions are redirected to waste. By the estimates it is feasible to process cuttings that have reusable surface area above $1 \mathrm{~m}^{2}$, otherwise adhesive consumption is too high to be rational. All cuttings were cut to $90^{\circ}$ corners. Only panels with identical layering and surface layer orientation were pressed together to guarantee the same mechanical strength. In this scenario, only spruce wood CLT is used. After multiple tests, Henkel Purbond S109/S309 adhesive was chosen for reprocessing of the cuttings. To maximise the working area for adhesive, $50 \mathrm{~mm}$ horizontal 
finger joint cuts with $12 \mathrm{~mm}$ step were made (Fig. 1), after manual application of the adhesive, panels were pressed together continuously and cut to required master panel dimensions.

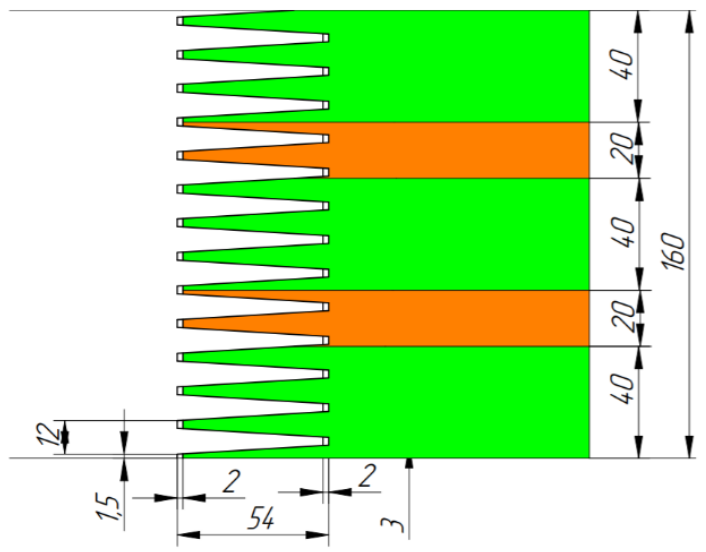

Fig. 1. Schematic representation of finger joint cut of 5-layer CLT (green - perpendicular cut to wood grain, orange parallel cut to wood grain). Units in $\mathrm{mm}$.

\subsection{Scenario of Individual House Project}

To illustrate the amount of available CLT for reprocessing, individual house project (Fig. 2) was chosen. Load bearing structure is entirely created from CLT. Doors and windows are cut out creating considerable amount of cutting waste.
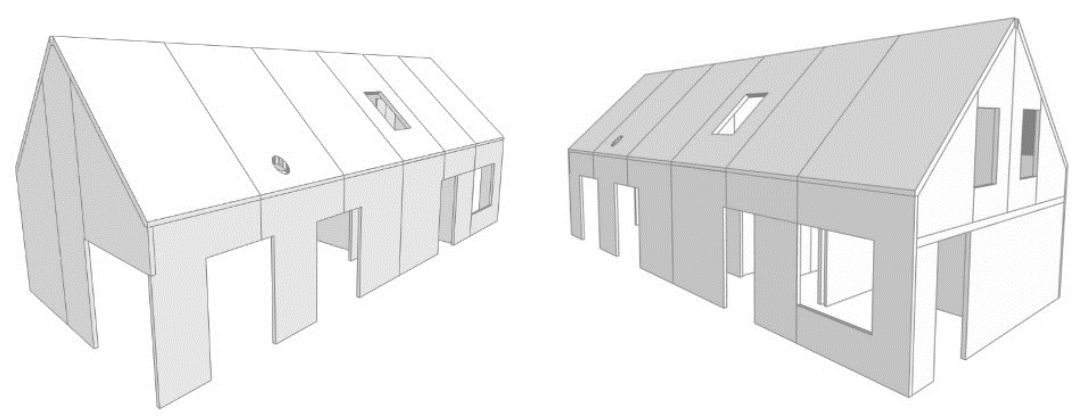

Fig. 2. 3D representation of individual house CLT weight bearing construction.

Not all the cuttings were suitable for new master panel production. Important criteria for cutting reuse was their flat surface area. Complicated geometrical shapes were sorted out, leaving the ones with reusable surface area above $1 \mathrm{~m}^{2}$ with dimensions along $\mathrm{X}$ axis (example shown in Fig. 3(A) not less than $800 \mathrm{~mm}$. 


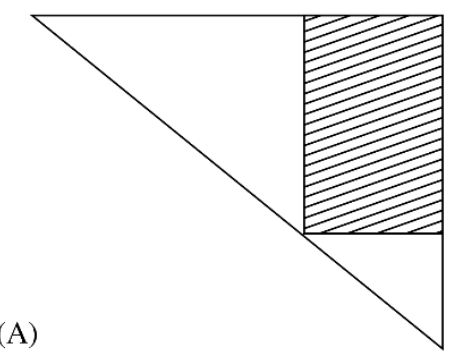

(B)

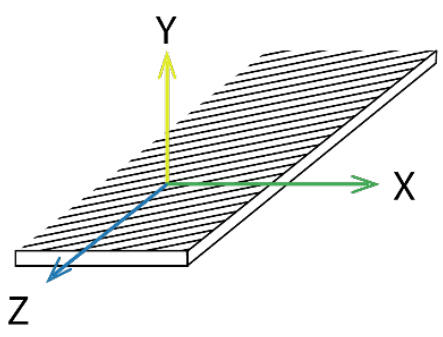

Fig. 3. (A) Reusable area of cutting represented with striped pattern. Width of the reusable area is $810 \mathrm{~mm}$ and length $1056 \mathrm{~mm}$; (B) schematic representation.

In chosen scenario for each house eight of the irregular cuttings were suitable for reprocessing into new master panels. To ensure efficient reprocessing, firstly the cuttings were calibrated to adjust the width ( $\mathrm{X}$ axis) so they could be adhered together and pressed perpendicular to $\mathrm{Z}$ axis, cut to desired master panel length of $3 \mathrm{~m}$ and after that gluing and pressing could be continued perpendicular the $\mathrm{X}$ axis (Fig. 3(B)). In this manner around $70 \%$ of the cuttings can be reprocessed into new $3 \times 6 \mathrm{~m}$ CLT panels. All the CLT cuttings from chosen individual house project.

As can be seen in Table 1, there are three types of CLT panels used $-80 \mathrm{~mm}, 120 \mathrm{~mm}$ and $150 \mathrm{~mm}$. By evaluating scenario of cutting re-processing from 10 individual houses, we are generating scenario where cuttings can be re-processed straight away, otherwise panels with $120 \mathrm{~mm}$ and $150 \mathrm{~mm}$ thickness will need to be stored in order to accumulate adequate quantity for reprocessing.

In order to continue with LCA, calculations based on acquired data were conducted. As a result, $18\left(29.7 \mathrm{~m}^{3}\right)$ pieces of re-processed master panels $(3 \times 6 \mathrm{~m})$ were produced and additional $6.23 \mathrm{~m}^{3}$ incomplete panels with $3 \mathrm{~m}$ by length that could be further used for new master panel production.

TABLE 1. CLT CUTTING ORIGINS AND DiMENSIONS

\begin{tabular}{llllll}
\hline \multirow{2}{*}{ Origin } & Thickness, & \multicolumn{2}{l}{ Cutting dimensions } & \multicolumn{2}{l}{ Dimensions after squaring } \\
& mm & Width, mm & Length, mm & Width, mm & Length, mm \\
\hline Door & 80 & 1525 & 2400 & 1525 & 2200 \\
Door & 80 & 1525 & 2400 & 1525 & 2200 \\
Door & 80 & 1525 & 2400 & 1525 & 2200 \\
Door & 80 & 1525 & 2400 & 1525 & 2200 \\
Door & 80 & 1237 & 2420 & 1025 & 2220 \\
Door & 80 & 1025 & 2400 & 1025 & 2200 \\
Window & 80 & 825 & 1425 & 810 & 1025 \\
Window & 80 & 825 & 1425 & 810 & 1025 \\
Door & 80 & 817 & 2400 & 810 & 2200 \\
Door & 80 & 825 & 2400 & 810 & 2200 \\
Door & 80 & 810 & 2220 & 810 & 2020 \\
\hline
\end{tabular}




\begin{tabular}{llllll}
\hline Door & 80 & 810 & 2220 & 810 & 2020 \\
Geometrical cutting & 80 & irregular & irregular & 810 & 1526 \\
Geometrical cutting & 80 & irregular & irregular & 810 & 1478 \\
Geometrical cutting & 80 & irregular & irregular & 810 & 1056 \\
Geometrical cutting & 80 & irregular & irregular & 810 & 1016 \\
Geometrical cutting & 80 & irregular & irregular & 810 & 921 \\
Geometrical cutting & 80 & irregular & irregular & 810 & 1396 \\
Geometrical cutting & 80 & irregular & irregular & 810 & 866 \\
Geometrical cutting & 80 & irregular & irregular & 810 & 848 \\
Window & 80 & 1625 & 1625 & 1625 & 1225 \\
Window & 120 & 840 & 1520 & 840 & 1120 \\
Floor slab & 150 & 2420 & 3380 & 2420 & 2980 \\
\hline
\end{tabular}

\subsection{Life Cycle Assessment Methodology}

The life cycle assessment (LCA) methodology is the most common tool used to quantify and compare in a quantitatively manner the impacts from different products or processes such as the one under study. Every product (good or service) has a life cycle, from its design, then the resource extraction, transporting, production or manufacturing, commercialization, consumption or use, and final disposition. The LCA core is to collect and group the resource consumption, emissions to the environment and environmental exchanges in all activities, that are needed to produce a determined good, and translate them into comprehensive environmental impact categories [1], [2].

This allows to think beyond climate change, which is usually the main parameter judged when assessing environmental issues. The main advantage of LCA is the ability to analyse impacts from a global perspective, avoiding "burden-shifting" [3] by allowing the assessment in many and diverse impact categories, regularly summarized in climate change, stratospheric ozone depletion, tropospheric ozone creation (smog), eutrophication, acidification, toxicological stress on human health and ecosystems, resource depletion, water use, land use, noise, and others [4].

The most used methodology for performing LCA is the LCA ISO standard 14040 and 14044 where the principles and framework for LCA are described and the requirements and guidelines to perform the assessment presented. It is in ISO 14044, where the key four steps are defined: goal and scope, life cycle inventory, life cycle impact assessment, and life cycle interpretation [5]. Such steps will be covered in detail in the next section.

\subsection{Goal and Scope Definition}

The scope requires a clear description of the function and functional unit, system boundaries, methodology, and data requirements to sufficiently address the stated goal. This study was done as a comparative one where the waste treatment in the conventional scenario is assumed to be the same as reported in [6], meaning it is assumed the CLT cuttings are used for energy recovery, more specifically in district heating and electricity production. However, transport of cuttings is not considered neither in this nor in the new proposed scenario, where cuttings are re-processed in-situ to generate new CLT pieces. Thus, the scope of this study is to evaluate only the activities related to the use given to cuttings in both scenarios despite of the geographical location with respect to the waste treatment facility. 
This is an attributional model where output data from [6] is normalized to the current scenarios considering the specific activities, material and energy flows required to conduct the re-process of cuttings for a specific residential construction project in Latvia. Then, the results of this study are only applicable to this scenario as foreground data was obtained directly from construction companies and the amount of cuttings subject to waste or reprocess may vary from one project to another, as well as foreground data related to materials and energy.

For the baseline scenario, the intended waste treatment is energy recovery, and the values for electricity, and heat generated are taken directly from [6] as well as the related impact from this End-of-Life (EoL) stage. Then, the impact results are normalized to the amount of waste expected from the construction project under evaluation, and these values are understood as the environmental impact results in the different mid-point categories resulting from the Environmental Product Declaration (EDP) methodology. For the proposed scenario, the same amount of cuttings resulting from the construction site, instead of being sent to the waste treatment plant, are re-processed to create useful new CLT units that could be even sold to other projects or used internally within the same building site. However, despite of the reprocessing activity, there are cuttings still left for waste, and it is assumed those leftovers are disposed in the same way as in the baseline scenario.

The EDP method has been recently updated (2018) including water scarcity footprint category, yet since the 2013 EDP version under which the Environmental Product Declaration was obtained for this CLT material did not include such category, this one has been left out of this study to keep comparison consistency. The LCA performed in this project was completed using Simapro 9.0 software integrated with Ecoinvent 3.6 database.

\subsubsection{Functional Unit}

The functional unit (FU) is a measure of the performance of the functional outputs of the product system and its main objective is to give a reference to which the inputs and outputs are related. Such a reference is needed to guarantee the equivalence of LCA results. The definition of a functional unit must then include both the quantitative and the key qualitative aspects to prevent subjectivity when subsequently defining an equivalence. In this case, the functional unit is one cubic meter $\left(1 \mathrm{~m}^{3}\right)$ of CLT material used in the construction site.

\subsubsection{System Boundaries}

Considering the Environmental Product Declaration system boundaries for the material under study and the system boundaries considered there, the scheme presented in Fig. 4 has been developed for this LCA.

The system boundaries in the baseline scenario only covers the waste treatment of cuttings generated in the construction site without bearing in mind transport to waste treatment plant since the distance is considered an uncertainty due to variability of possible geographical locations of building sites. Please notice although phases A1-B7 are displayed in the figure, only those phases inside the dashed box are the ones within the study's system boundaries. Extra phases are only informative to show the overall life cycle of CLT.

For the proposed scenario, the re-process activity is carried out in-situ, without any need for transport to another location. The remaining cuttings not fitted to be re-processed are disposed using the same treatment technology considered for the baseline scenario, and again, the transport to the waste treatment facility is not considered due to distance uncertainty. 


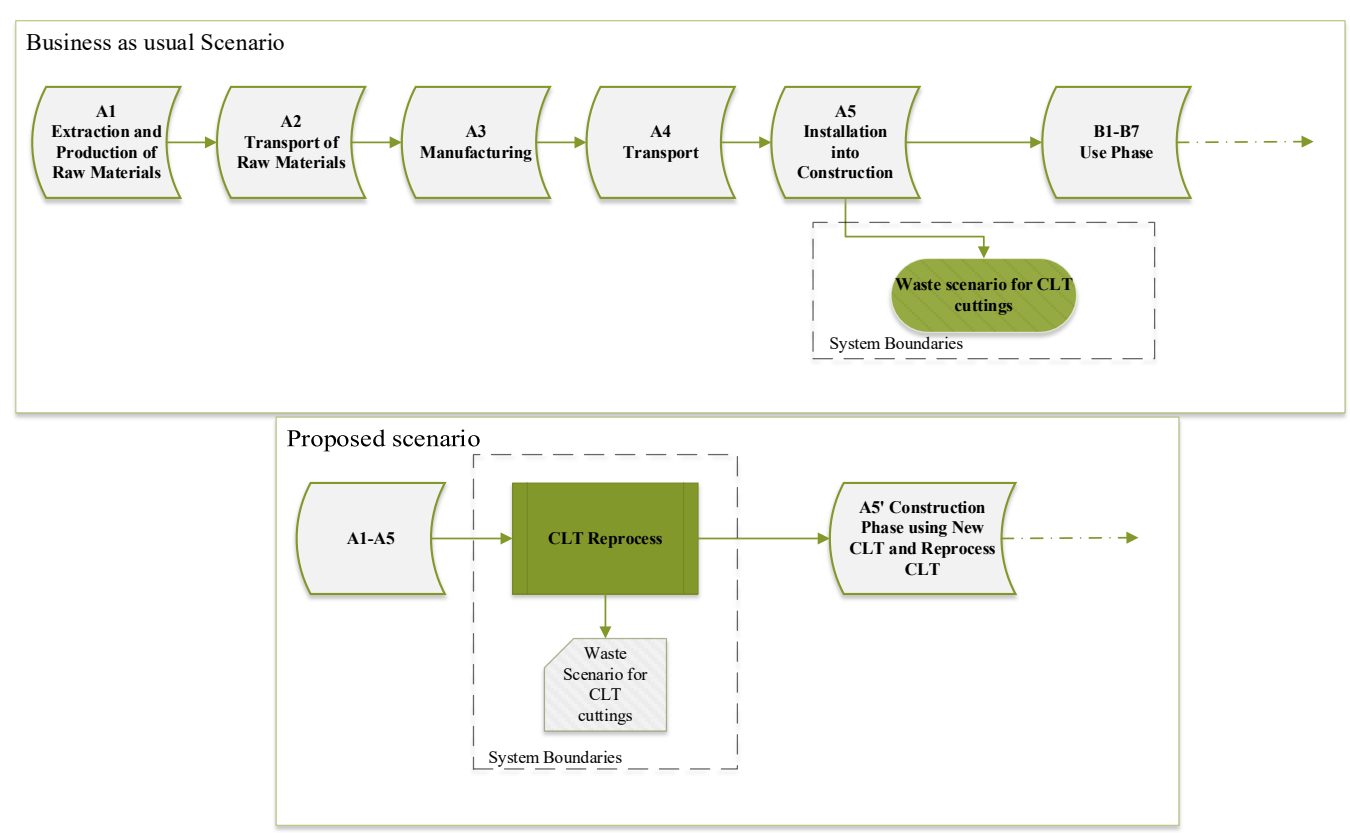

Fig. 4. System boundaries for the business as usual and proposed scenarios.

\subsubsection{Limitations and Assumptions}

Among the limitations that apply for the two scenarios under comparison, the exclusion of transport activities is the main one due to the uncertainty on both: the geographical location of the waste treatment facility and the construction site as it varies depending on the project. However, it is important to notice, that transporting wastes does come with an environmental burden from the vehicle itself and the fuel combustion, moreover, the higher the amount of waste to be transported, the higher the environmental impact will be; hence it is likely that by reducing the amount of waste subject to transported, an additional environmental benefit might be perceived despite not been accounted for in this study.

Another assumption to bear in mind is the fact of the re-process being carried out in the same location as the construction of the residential houses is taking place. This is important since it might be possible, under different case studies, that cuttings leftover after construction need to be sent to another location for re-processing and then dispatched back to the same location or sold to another construction project in a different one. For this cases study, since the re-processing activities are conducted in the same place, no additional environmental toll from transport is created.

\subsection{Life Cycle Inventory}

For the baseline scenario, the results from the energy recovery at the end of life (EoL) stage in [6] were taken directly for $1 \mathrm{~m} 3$ and normalized to the amount of waste generated in the particular construction site. According to the foreground data collected, per each cubic meter of CLT used, $0.128 \mathrm{~m}^{3}$ end up as cuttings leftover to waste. The benefits resulting from the energy recovery of $1 \mathrm{~m}^{3}$ are estimated in $612 \mathrm{MJ}$ of electricity and $4208 \mathrm{MJ}$ of thermal energy for district heating. Their associated environmental impact is shown in Table 2 for a whole cubic meter of material disposed. Nevertheless, the values within the model are normalized to the actual amount of cuttings sent to waste in each scenario. 
TABLE 2. IMPACT ASSESSMENT FOR $1 \mathrm{M}^{3}$ OF CLT DiSPOSED

\begin{tabular}{lll}
\hline Impact category & Unit & Total per $\mathbf{~ m}^{\mathbf{3}}$ \\
\hline Acidification Potential & $\mathrm{kg} \mathrm{SO}_{2}$ eq & -0.1786 \\
Eutrophication Potential & $\mathrm{kg} \mathrm{PO}_{4}$ eq & -0.04186 \\
Global Warming Potential & $\mathrm{kg} \mathrm{CO}_{2}$ eq & -32.51 \\
Formation potential of tropospheric photochemical oxidants & $\mathrm{kg} \mathrm{C}_{2} \mathrm{H}_{4} \mathrm{eq}$ & -0.01664 \\
Abiotic depletion potential for non-fossil resources & $\mathrm{kg} \mathrm{Sb}$ eq & -0.000112 \\
Abiotic depletion potential for fossil resources & $\mathrm{MJ}$ & -0.04217 \\
Depletion potential of the stratospheric ozone layer & $\mathrm{kg} \mathrm{CFC}-11 \mathrm{eq}$ & 0.000004012 \\
\hline
\end{tabular}

For the proposed scenario where re-process activities allow to recover part of the cuttings by making new CLT units, the inventory collection goes toward gathering impacts from 3 stages:

1. Production of brand new CLT units;

2. Materials and energy required for the re-process activity itself;

3. The waste treatment of the unrecoverable cuttings.

Since by creating new CLT units from cuttings, brand new CLT units are potentially replaced in a construction site, the impact of such new re-processed CLT units are considered as an avoided product, hence the environmental impact results from phases A1-A3 (Fig. 1) are normalized and mathematically treated consequently with this approach. Impacts of stages A1-A3 for $1 \mathrm{~m}^{3}$ are shown in Table 3 .

TABle 3. IMPACt Assessment of Producing $1 \mathrm{M}^{3}$ of CLT (A1-A3 Stages)

\begin{tabular}{lll}
\hline Impact category & Unit & Total \\
\hline Acidification Potential & $\mathrm{kg} \mathrm{SO}_{2} \mathrm{eq}$ & 0.6272 \\
Eutrophication Potential & $\mathrm{kg} \mathrm{PO}_{4} \mathrm{eq}$ & 0.1116 \\
Global Warming Potential & $\mathrm{kg} \mathrm{CO}_{2} \mathrm{eq}$ & -0.05673 \\
Formation potential of tropospheric photochemical oxidants & $\mathrm{kg} \mathrm{C}_{2} \mathrm{H}_{4} \mathrm{eq}$ & 0.1144 \\
Abiotic depletion potential for non-fossil resources & $\mathrm{kg} \mathrm{Sb}^{\mathrm{eq}}$ & 0.0002468 \\
Abiotic depletion potential for fossil resources & $\mathrm{MJ}$ & 1497 \\
Depletion potential of the stratospheric ozone layer & $\mathrm{kg} \mathrm{CFC}-11 \mathrm{eq}$ & 0.0000125 \\
\hline
\end{tabular}

The inventory of material and energy required for re-processing $0.128 \mathrm{~m}^{3}$ of leftover cuttings (value per FU), are normalized to the following: $0.0904 \mathrm{~kg}$ of adhesive (polyurethane adhesive) and $0.466 \mathrm{kWh}$ of electricity taken from the national grid. According to the foreground data obtained, $69.72 \%$ of the cuttings re-processed are successfully converted into new CLT modules while the remaining 30.28 \% are not suitable for re-process and must be left as waste material for treatment. Again, the impact related to such treatment is taken from Table 1 and normalized to the corresponding value in this scenario.

\section{Life CYClE IMPACT ASSESSMENT AND INTERPRETATION}

The proposed case scenario where cuttings from CLT are re-processed was modelled in SimaPro according to the defined FU and the results are presented first in a comparative way with the business-as-usual scenario, and then it is disaggregated by unit process. The impact 
assessment is presented at midpoint level ( $\mathrm{kg}$ of substance equivalent) as recommended by the EDP method and ISO standards in Table 4. Results in business-as-usual scenario correspond to the energy recovery phase for $0.128 \mathrm{~m}^{3}$ of CLT; on the other hand, the results in the proposed scenario correspond to the sum of the three considerations aforementioned: impact from the re-process activity, avoided impact from putting in the market new CLT modules, and the impact related to the energy recovery of remaining cuttings not reprocessed.

\section{TABLE 4. CHARACTERIZATION RESULTS COMPARISON BETWEEN SCENARIOS}

\begin{tabular}{llll}
\hline Impact category & Unit & Business as usual & Proposed scenario \\
\hline Acidification Potential & $\mathrm{kg} \mathrm{SO}_{2}$ eq & -0.023 & -0.059 \\
Eutrophication Potential & $\mathrm{kg} \mathrm{PO}_{4} \mathrm{eq}$ & -0.005 & -0.011 \\
Global Warming Potential & $\mathrm{kg} \mathrm{CO}_{2} \mathrm{eq}$ & -4.155 & -0.524 \\
Formation potential of tropospheric photochemical & $\mathrm{kg} \mathrm{C}_{2} \mathrm{H}_{4} \mathrm{eq}$ & -0.002 & -0.008 \\
oxidants & & & \\
Abiotic depletion potential for non-fossil resources & $\mathrm{kg} \mathrm{Sb}$ eq & $-1.43 \mathrm{E}-05$ & $-2.35 \mathrm{E}-05$ \\
Abiotic depletion potential for fossil resources & $\mathrm{MJ}$ & -0.005 & -122.457 \\
Depletion potential of the stratospheric ozone layer & $\mathrm{kg} \mathrm{CFC}-11$ eq & $5.13 \mathrm{E}-07$ & $-9.20 \mathrm{E}-07$ \\
\hline
\end{tabular}

In the business-as-usual scenario, most of the impact categories show a benefit to the environment since it is understood, that the electricity and thermal energy generated from the incineration of CLT material would replace conventional electricity production in Latvia, according to the market for electricity mix in the Ecoinvent 3.6 database. In the proposed scenario, even higher benefits to the environment are obtained, due to the still energy recovery for $30.28 \%$ of the leftover cuttings and the delivered avoided impact from new CLT modules.

Percentual changes of moving from a business-as-usual scenario towards the proposed one are easily seen in Fig. 5.

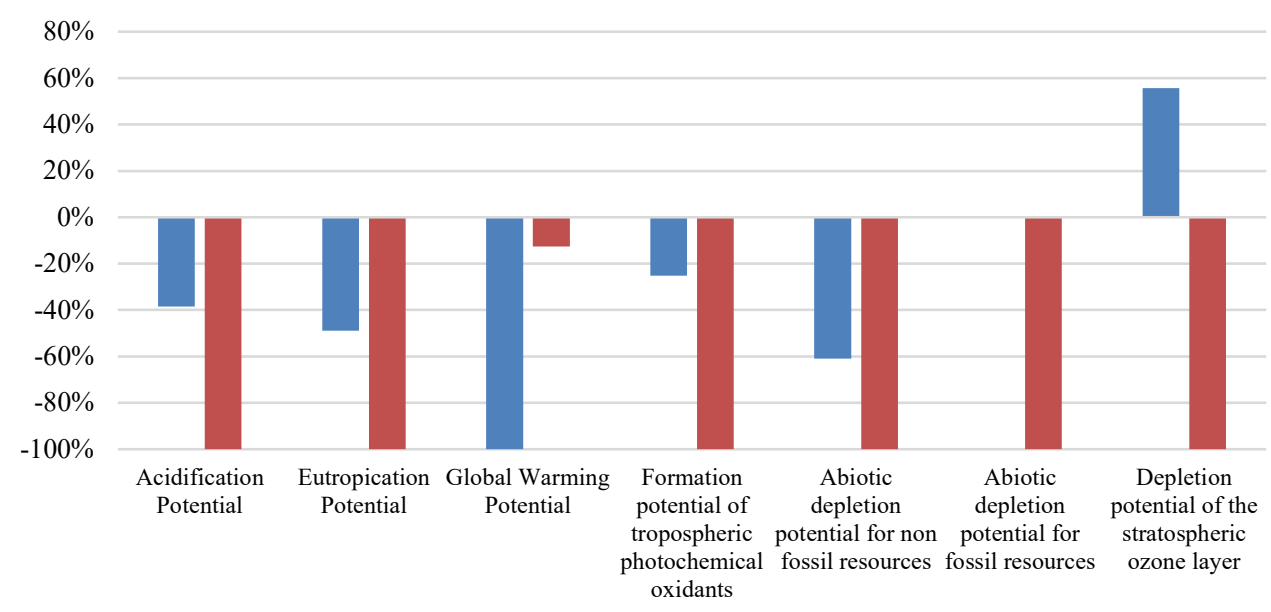

Waste treatment in Business as usual $\quad$ Proposed scenario (re-process)

Fig. 5. Characterization results. 
In general, the nowadays EoL stage or waste treatment of CLT delivers benefits to the environment in almost all the impact categories assessed within the EDP method, but for the ozone layer depletion one. Nevertheless, the proposed new set of activities that give birth to new CLT panels reducing the amount of waste to be incinerated, aids to increase the already delivered benefits in all areas except for the global warming potential, this as result of the lower electricity production that would have eventually substitute the production from conventional sources in the specific Latvian market. It is worth to notice that the GWP benefits under the business-as-usual scenario is due to the fact of substituting energy production from the local market by the energy recovery from a one hundred percent renewable source such as wood. In all other areas benefits from the new approach surpasses the original ones.

Regarding the proposed re-processing of CLT cuttings scenario, the adverse effects to the environment are coming from the re-process activity, since the waste scenario is the same as for the business as usual, thus resulting in an environmental benefit, and the new produced CLT modules are considered as an avoided product. Under the evaluation of the proposed scenario, it was found the main driver in most of the evaluated impact categories is the use of polyurethane adhesive (Fig. 6), except in the ozone layer depletion one.

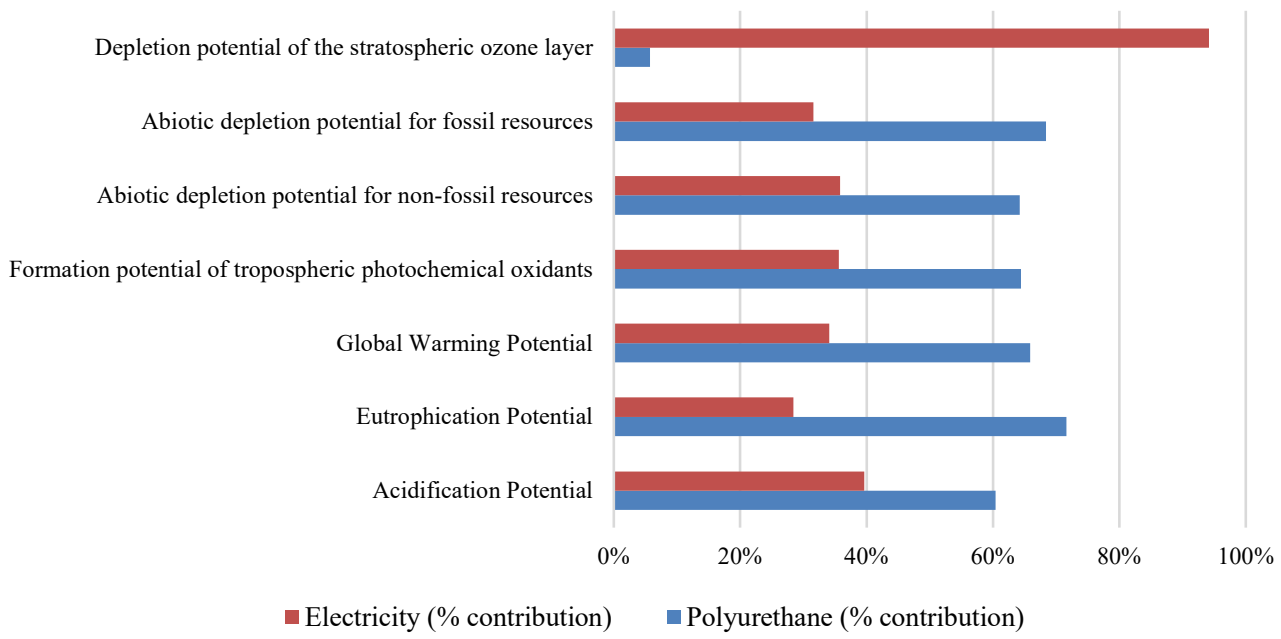

Fig. 6. Environmental impact contribution per re-processing activity/flow.

\section{Discussion}

Several studies regarding the environmental impact of using CLT as a substitute material for concrete or just as a building material, from cradle to grave are found in the literature for different geographic scenarios such as Australia [10], The United States [15], Europe [16] and Japan [17] just to mention some. In most cases it is stated that the use of CLT is advantageous as its main raw material can be linked to a renewable source, which promotes Bio Energy Carbon Capture and storage, circular economy by implementing energy recovery in the EoL stage, and in general, all LCA prove CLT to be environmentally friendly.

Still, the construction activities deal with a lot of cuttings that result in CLT material waste, hence most of the quantitative environmental benefit linked to it that comes from the 
comparison with typical building supplies is now lost, and the benefit of CLT can only be related to how it is disposed. In this work, a new way of dealing with CLT wastes from construction sites is addressed to and evaluated using LCA and the EDP method to allow comparison with the EoL stage reported in the EDP declaration for the CLT manufacturer in Latvia case [18].

The results of conducted LCA show that eco-efficiency regarding CLT cutting reprocessing is beneficial, as cutting re-processing allows for considerable amount of avoided product. Data showed that re-processing consumes considerably less resources than new CLT production in turn leading to lower environmental impact. Only impact category where business as usual showed better results is global warming potential category, as explained previously - this is due to thermal and electric energy recovery from business-as-usual waste treatment. As almost $30 \%$ of CLT cuttings goes to waste after reprocessing, proposed scenario benefits from incineration activities as well. At this point CLT re-processing technology is limited to $800 \mathrm{~mm}$ width dimensions and arguably it will not be viable to process smaller cuttings, as this approach would increase the consumption and end concentration of adhesive. As results (Table 4) show, greatest driver of impact in all categories is PU adhesive. Literature shows that conventional adhesives like ureaformaldehyde have significantly negative impacts on emissions, toxicity, eutrophication and acidification. Even if most of EWP contain resins like urea-formaldehyde, environmental impacts of EWP are lower than other types of building materials [19]. Nevertheless, as the adhesive creates the biggest environmental burden, materials with higher adhesive amount does as well. Hence from environmental point of view smaller cutting re-processing will not be feasible.

Positive results regarding the reduction of environmental impact shows that CLT reprocessing technology should be explored further as it can potentially reduce the environmental impact of all CLT industry. As mentioned in this paper, rapid growth is predicted for CLT and another EWP. Building with CLT instead of concrete will allow for construction industry to transition towards more sustainable model. Recent signals from European Union [20] as well as older ones from United Nations [21] confirm the policy changes regarding efficient material use and re-processing. Hence, developing technology for CLT waste re-processing whilst the CLT technology is being developed itself corresponds to 21 st century's green approach and aligned with the European and global goals of achieving sustainability and carbon neutrality.

\section{ACKNOWLEDGMENT}

This study was carried out with the support of CFLA contract No. 1.2.1.1/18/A/004 between "Forest Sector Competence Centre of Latvia" Ltd. and the Central Finance and Contracting Agency, the study is conducted by "FUNDUSS" Ltd. with support from the European Regional Development Fund (ERDF) within the framework of the project "Forest Sector Competence Centre"

\section{REFERENCES}

[1] M. Lavagna et al. Benchmarks for environmental impact of housing in Europe: Definition of archetypes and LCA of the residential building stock. Build. Environ. 2018:145:260-275. https://doi.org/10.1016/j.buildenv.2018.09.008

[2] Communication From The Commission To The European Parliament, The Council, The European Economic And Social Committee And The Committee Of The Regions On Resource Efficiency Opportunities In The Building Sector. Brussels: European Commission, 2014. 
[3] Müller H. S., Haist M., Vogel M. Assessment of the sustainability potential of concrete and concrete structures considering their environmental impact, performance and lifetime. Constr. Build. Mater. 2014:67(C):321-337. https://doi.org/10.1016/j.conbuildmat.2014.01.039

[4] Athena Sustainable Materials Institute. A Life Cycle Assessment of Cross-Laminated Timber Produced in Canada. Ottawa: Athena Sustainable Materials Institute, 2013.

[5] IEA. Global cement production, 2010-2019 - Charts - Data \& Statistics - IEA [Online]. [Accessed 30.10.2020]. Available: https://www.iea.org/data-and-statistics/charts/global-cement-production-2010-2019

[6] Wood Based Panel Market Size \&amp; Share | Industry Report, 2018-2025 [Online]. [Accessed 09.02.2021]. Available: https://www.grandviewresearch.com/industry-analysis/wood-based-panel-market

[7] Panels \& Furniture Asia May/Jun 2020 [Online]. [Accessed: 28.10.2020]. Available: http://www.panelsfurnitureasia.com/ebook/PFA_MayJun2020/index.html

[8] Cherry R., et al. Out-of-grade sawn pine: A state-of-the-art review on challenges and new opportunities in cross laminated timber (CLT). Constr. Build. Mater. 2019:211:858-868. https://doi.org/10.1016/j.conbuildmat.2019.03.293

[9] Hildebrandt J., Hagemann N., Thrän D. The contribution of wood-based construction materials for leveraging a low carbon building sector in europe. Sustain. Cities Soc. 2017:34:405-418. https://doi.org/10.1016/j.scs.2017.06.013

[10] Jayalath A., et al. Life cycle performance of Cross Laminated Timber mid-rise residential buildings in Australia. Energy Build. 2020:223:110091. https://doi.org/10.1016/j.enbuild.2020.110091

[11] Hemström K., Mahapatra K., Gustavsson L. Perceptions, attitudes and interest of Swedish architects towards the use of wood frames in multi-storey buildings. Resour. Conserv. Recycl. 2011:55(11):1013-1021. https://doi.org/10.1016/j.resconrec.2011.05.012

[12] Cabinet of Ministers. Ministru kabineta noteikumi Nr. 333: Noteikumi par Latvijas būvnormatīvu LBN 201-15 "Būvju ugunsdrošība" (Regulations of the Cabinet of Ministers No. 333: Regulations on the Latvian construction standard LBN 201-15 "Fire safety of buildings"). Latvijas Véstnesis 2015. (in Latvian)

[13] OECD. How's Life? Measuring well-being. Paris: OECD, 2017.

[14] Barboutis I. Kamperidou V. Properties of two different thicknesses 3-ply plywood of tree-of-heaven veneers. Proceedings of the 22nd Int. Sci. Conf. Wood is Good-EU Preaccession Challenges Sect. Proc. 2011:6-19.

[15] Chen C. X., Pierobon F., Ganguly I. Life Cycle Assessment (LCA) of Cross-Laminated Timber (CLT) produced in Western Washington: The role of logistics and wood species mix. Sustain. 2019:11(5):1278. https://doi.org/10.3390/su11051278

[16] Guardigli L., Monari F., Bragadin M. A. Assessing environmental impact of green buildings through LCA methods: A comparison between reinforced concrete and wood structures in the European context. Procedia Eng. 2011:21:1119 1206. https://doi.org/10.1016/j.proeng.2011.11.2131

[17] Passarelli R. N. Environmental Benefits of Reusable Modular Mass Timber Construction for Residential use in Japan: an LCA Approach. Modul. Offsite Constr. Summit Proc. 2019:2017:157-164. https://doi.org/10.29173/mocs89

[18] Giels E. Cross laminated timber panels. Oslo: Epd-Norge, No. 2017.

[19] Sathre R., González-García S. Life cycle assessment (LCA) of wood-based building materials. Eco-Efficient Construction and Building Materials. Life Cycle Assessment (LCA), Eco-Labelling and Case Studies. Woodhead Publishing, 2014:331-337. https://doi.org/10.1533/9780857097729.2.311

[20] Tubert-Brohman I., Sherman W., Repasky M., Beuming T. Improved Docking of Polypeptides with Glide J. Chem. Inf. Model. 2013:53(9):1689-1699. https://doi.org/10.1021/ci400128m

[21] Ichimura M., et al. Eco-efficiency Indicators: Measuring Resource-use Efficiency and the Impact of Economic Activities on the Environment. Bangkok: United Nations publication, 2009. 